Kansas State University Libraries

New Prairie Press

\title{
SAMPLING PLANS FOR MONITORING RUST IN COFFEE TREES
}

Raw E. Macchiavelli

Roclo Rodriguez

Follow this and additional works at: https://newprairiepress.org/agstatconference

Part of the Agriculture Commons, and the Applied Statistics Commons

\section{(c) $($ ) $\ominus$}

This work is licensed under a Creative Commons Attribution-Noncommercial-No Derivative Works 4.0 License.

\section{Recommended Citation}

Macchiavelli, Raw E. and Rodriguez, Roclo (1998). "SAMPLING PLANS FOR MONITORING RUST IN COFFEE TREES," Conference on Applied Statistics in Agriculture. https://doi.org/10.4148/2475-7772.1287

This is brought to you for free and open access by the Conferences at New Prairie Press. It has been accepted for inclusion in Conference on Applied Statistics in Agriculture by an authorized administrator of New Prairie Press. For more information, please contact cads@k-state.edu. 


\title{
SAMPLING PLANS FOR MONITORING RUST IN COFFEE TREES
}

\author{
Raúl E. Macchiavelli and Rocío Rodríguez \\ College of Agriculture, University of Puerto Rico \\ P.O. Box 9030, Mayagüez, PR 00681-9030
}

\begin{abstract}
Rust is an important fungal disease of coffee that causes defoliation of plants, thus affecting production and yield of coffee beans. Management of coffee rust with fungicides should be based on disease incidence at the onset of the epidemic. Previously, sampling has been done in a two-step systematic plan: trees are sampled in a systematic pattern (in the shape of a W covering the field), and then leaves are randomly sampled within each selected tree. Since coffee in Puerto Rico is typically grown in areas with pronounced slopes, these plans require walking diagonally along slopes, which is not feasible for regular monitoring by farmers. In this work we compare different sampling plans in order to find one which can be carried out by the farmers and permits the efficient estimation of the disease incidence. Alternative methods are shown by simulation to be as efficient as the traditionally used plans under patterns of spatial dispersion similar to the ones present in the field.
\end{abstract}

\section{Introduction}

Coffee (Coffea arabica L.) is the major crop in Puerto Rico. The importance of this commodity not only lies in its value to the overall agricultural income generated by crops, but also in that it sustains $9 \%$ of the population of the island, employing 9,000 to 11,000 laborers in the rural areas (Monroig-Inglés, 1988).

In February 1989, rust (Hemileia vastatrix) was detected in Puerto Rico. This is the most serious disease of coffee in this hemisphere. The activities of the pathogen in the plant reduce the quantity and quality of coffee beans by affecting photosynthesis, inducing defoliation and reducing plant vigor (Kushalappa, 1989). Chemical control is one of the strategies for controlling the disease. Thus far, frequent applications of several fungicide formulations have been identified as effective in reducing rust incidence. Timing for spraying with fungicides are based primarily on disease progress curves, regardless of the actual incidence at the moment. However, rust is distributed in foci and not all areas in the coffee plantation are, or will be, affected with the same intensity. Because of this uneven distribution and the fact that disease incidence varies with years, the decision to spray with fungicides should be based on disease levels at specific months and sites within the plantation. 
Methods for monitoring this disease have been adapted from other diseases and crops. Sampling is done in a two-step plan: trees are sampled in a systematic pattern, and then leaves are randomly sampled within each selected tree. Following Campbell and Madden (1990), a systematic pattern in a W form covering the field "seems to perform adequately in most situations when propagules are aggregated." In the case of coffee fields in Puerto Rico, this methodology is highly impractical, since coffee is grown in areas with pronounced slopes. This implies, for the person doing the monitoring, walking diagonally along slopes, making it almost impossible to keep track of the systematic pattern. In this paper we study alternative methods of collecting samples, and of deciding how many trees and leaves per tree to sample.

\section{Material and methods}

Two coffee fields in the Adjuntas Experiment Station (University of Puerto Rico) were used in this study, one with variety "Caturra" and the other with variety "Bourbon". Both fields are typical of the conditions under which coffee is grown in Puerto Rico: pronounced slopes with rows of trees along them, and large variability in disease intensity (ranging from 0 to $80 \%$ of infected leaves). Coffee trees are planted in rows, at a distance of 6 feet between rows and 4 feet between trees in the same row. Given the complex structure of the spatial dispersion of this disease, the problem was approached through simulations using the SAS system (SAS, 1990).

The response of interest in the monitoring is the "disease index", $\delta$, for each tree:

$$
\delta=\frac{\text { number of infected leaves in the middle third of the tree }}{\text { total number of leaves in the middle third of the tree }}
$$

The decision of applying fungicides is based on the disease index averaged over all trees in the lot, $\bar{\delta}$. In the two-step sampling procedure ( $n$ trees sampled out of $N$ trees in the field, and $m$ leaves sampled in each tree out of $M_{i}$ leaves in the $i$-th tree), the estimator of $\bar{\delta}$ is:

$$
\bar{d}=\frac{\sum_{i} d_{i}}{n},
$$

where $d_{i}$ is the sample disease index for the $i$-th tree.

In order to estimate the variance of $\bar{d}$, the formula presented in Steel and Torrie (1980) for two-stage finite population sampling with binomial-type response can be modified to account for the different number of leaves per tree:

$$
\widehat{\operatorname{Var}}(\bar{d})=\frac{1}{N n(m-1)} \sum_{i=1}^{n} \frac{M_{i}-m}{M_{i}-1} d_{i}\left(1-d_{i}\right)+\frac{N-n}{N n} \sum_{i=1}^{n} \frac{\left(d_{i}-\bar{d}\right)^{2}}{n-1}
$$

Since the first stage in the sampling designs to be used in this paper is systematic, this formula is only an approximation. 


\section{Preliminary selection of the number of leaves per tree}

Since it is impossible to analyze all leaves in all trees in the field (it is normally done by cutting the leaves), the first step was to select a number of leaves per tree which could yield good estimates of $\bar{\delta}$. In order to accomplish this, 50 trees from each cultivar (Caturra and Bourbon) were randomly chosen. Since the disease is concentrated in the middle third of the coffee tree, all leaves in this area were counted and diagnosed for symptoms of rust. Hence the "true" disease index was known for each of the 50 trees of each cultivar. To prevent unnecessary damage and stress to the trees, the evaluation was done without detaching the leaves.

Using a SAS macro, we simulated sampling between 10 and 100 leaves per tree, and 20,30, 40 and 50 trees. For each combination of number of trees and number of leaves per tree we repeated the simulations 500 times, computing the mean and the standard error of $\bar{d}$.

The results were consistent for both cultivars and all values of $n$ studied, and are summarized in Figures 1 and 2. From these figures we can see that the variance decreases quickly when only a few leaves per tree are sampled, but then it stabilizes. Hence, it seems that 40 leaves per tree yields a reliable approximation to the true $\bar{\delta}$, and that additional leaves increase the precision of the estimate very little. Hence in the next step we will evaluate 40 leaves per tree in all trees in the Caturra field.

\section{Selection of the sampling plan}

In order to select the sampling plan which will be recommended to the farmer, we sampled all trees in the Caturra lot $(N=1269)$ and cut 40 leaves per tree from the middle third. This allows us to study different sampling patterns and the spatial dispersion of this disease. The chosen field is typical of the coffee fields found in Puerto Rico, and had disease indices varying from 0 to .825 . The average disease index in this lot was .1939, with a standard deviation of .1742 .

Two systematic patterns were chosen: a traditional $\mathrm{W}$ pattern and a more feasible one in parallel rows. The pattern in $\mathrm{W}$ takes samples from trees systematically along a row (every $c$ trees, with $c$ varying from 2 to 6 ) up to one extreme of the field, then diagonally every $c$ trees up to the other extreme, then diagonally and along a row every $c$ trees in the opposite direction. The pattern of parallel rows takes samples, along 4 equally spaced parallel rows, every $c$ trees, with $c$ varying from 2 to 7 . Simulations were carried out in SAS for sampling 2, 5, 10,20,30 and 40 leaves per tree every $c$ trees. For each of the 66 cases we simulated 500 independent runs, and computed the mean and the standard error of $\bar{d}$.

The means of $\bar{d}$ indicate that the $\mathrm{W}$ pattern tends to overestimate the true average disease index (.1939), since in $90 \%$ of the cases the means are larger than the true value, 
ranging from .185 to .244 . On the other hand, the parallel rows samples had means ranging from .177 to .210 , with essentially half of the values $(53 \%)$ above the true disease index.

Figures 3 and 4 show the standard errors obtained for sampling in parallel rows and in a $\mathrm{W}$ pattern, respectively. From these figures we can see that the standard errors for both methods are comparable, and that sampling 5 or 10 leaves per tree for a total of approximately 20 trees (equivalent to sampling every sixth tree in either pattern) attains acceptable standard errors.

\section{Spatial distribution}

In order to make more general recommendations for monitoring this disease, we studied the spatial ditribution pattern of the disease index in the Caturra field. Campbell and Madden (1990) recommend the use of spatial autocorrelation models to describe the spatial dispersion. We applied different correlation models to our data and used BIC information criterion (Schwarz, 1978) to select the best simple model explaining the correlation structure of the data.

The MIXED procedure in SAS (1997) with the following correlation functions was used:

1. Exponential:

$$
\operatorname{Cov}\left(d_{i}, d_{j}\right)=\sigma^{2} \exp \left(\frac{-\operatorname{dist}(i, j)}{\rho}\right),
$$

where $\operatorname{dist}(i, j)$ is the distance, in feet, between trees $i$ and $j$.

2. Anisotropic Exponential:

$$
\operatorname{Cov}\left(d_{i}, d_{j}\right)=\sigma^{2} \exp \left(-\theta_{x}\left(\operatorname{dist}_{x}(i, j)\right)^{p_{x}}\right) \exp \left(-\theta_{y}\left(\operatorname{dist}_{y}(i, j)\right)^{p_{y}}\right),
$$

where $\operatorname{dist}_{x}(i, j)$ and $\operatorname{dist}_{y}(i, j)$ are the distances between trees $i$ and $j$ along the row and across rows, respectively.

3. Power:

$$
\operatorname{Cov}\left(d_{i}, d_{j}\right)=\sigma^{2} \rho^{\operatorname{dist}(i, j)}
$$

4. Anisotropic Power:

$$
\operatorname{Cov}\left(d_{i}, d_{j}\right)=\sigma^{2} \rho_{x}^{\operatorname{dist}_{x}(i, j)} \rho_{y}^{\operatorname{dist}_{y}(i, j)} .
$$

5. Spherical:

$$
\operatorname{Cov}\left(d_{i}, d_{j}\right)=\sigma^{2}\left[1-\frac{3 \operatorname{dist}(i, j)}{2 \rho}+\frac{\operatorname{dist}^{3}(i, j)}{2 \rho^{3}}\right] I(\operatorname{dist}(i, j) \leq \rho) .
$$


Table 1: Values of Schwarz's BIC criterion for the covariance structures used

\begin{tabular}{|l|c|}
\hline Structure & BIC \\
\hline Exponential & 560.955 \\
Anisotropic exponential & 595.645 \\
Power & 560.955 \\
Anisotropic power & 536.375 \\
Spherical & 473.347 \\
\hline
\end{tabular}

These five structures were fitted and the results are summarized in Table 1.

From Table 1 it is clear that the most appropriate structure is the anisotropic exponential model, since this model has the highest BIC value. The estimated covariance between any two points for this model was:

$$
\widehat{\operatorname{Cov}}\left(d_{i}, d_{j}\right)=.0296 \exp \left(-.7180\left(\operatorname{dist}_{x}(i, j)\right)^{.1759}\right) \exp \left(-1.3582\left(\operatorname{dist}_{y}(i, j)\right)^{.2676}\right) .
$$

This equation indicates that there is a stronger correlation along a row (i.e., along the $\mathrm{x}$-coordinate) than across rows (i.e., along the y-coordinate).

An estimate of the standard error of $\bar{d}$ can be obtained from this model:

$$
\widehat{\operatorname{Var}}(\bar{d})=\frac{1}{n^{2}}\left[\sum_{i} \widehat{\operatorname{Var}}\left(d_{i}\right)+2 \sum_{i<j} \widehat{\operatorname{Cov}}\left(d_{i}, d_{j}\right)\right] .
$$

For the proposed sampling scheme (4 parallel rows, every sixth tree in each selected row), we can verify that the covariance between $d_{i}$ 's in different rows is never larger than .00046 , while the covariance between $d_{i}$ 's in the same row is at least .006 (for trees that are at the two extremes of a given row).

\section{Conclusions and recommendations}

From the results obtained in this study, it can be concluded that, for patterns of spatial dispersion similar to the ones found in the Caturra lot studied here, a pattern of systematic sampling in parallel rows performs better than a pattern in W, since it yields estimates of $\bar{\delta}$ closer to the true value of $\bar{\delta}$ and the standard errors are similar under both patterns. It is recommended that trees be sampled along 4 parallel rows (choosing the first row randomly among the first 10 rows). Each selected row should be separated from the previous one by 10 rows. Take 5 or 10 leaves every sixth tree along each selected row. If there is a missing tree in the chosen position, sample the next tree along the row. This plan should select approximately 20 trees in the lot of 1269 trees (about 1/60th of the trees). According to figures 3 and 4 , it seems more important to obtain more leaves in each tree than more trees. 
It is necessary to verify these recommendations under other spatial patterns. A future study will address this problem by simulating different sampling patterns assuming different parameters for the spatial dispersion.

Another issue that needs to be addressed is the estimation of the standard errors. In our study, the estimated standard errors, calculated using (3), were always smaller than the actual standard errors of $\bar{d}$ (calculated from the 500 values of $\bar{d}$ obtained). This could be due to the fact that (3) is developed for random sampling, while our plans are systematic and the dispersion is non random. Some formulas developed for systematic sampling could be introduced (Wolter, 1984), but they may need to be modified to account for the non random dispersion. The standard errors calculated using the covariance model estimated in section 5 were in general larger than the ones calculated from the 500 realizations of $\bar{d}$. A bootstrap estimate may be necessary, given that the incidence of this disease almost never presents random dispersion, since the disease is distributed in foci.

\section{Summary}

Alternative sampling plans for monitoring rust in coffee trees are compared through simultions with traditional plans proposed for plant diseases in other crops. The criteria for comparing plots are bias and standard error of the average disease index (average proportion of infected leaves). According to these criteria, a pattern of systematic sampling in parallel rows is recommended. Spatial models are used to estimate the covariance structure, giving alternative standard error estimates for the average disease index.

\section{Acknowledgments}

We want to thank Agronomists Wigmar González and Oswaldo Bosque for their assistance in collecting the data. We also want to thank two anonymous referees for their insightful comments.

\section{References}

[1] Campbell, C. L. and L.V. Madden (1990). Introduction to Plant Disease Epidemiology. New York: J. Wiley.

[2] Kushalappa, A.C. (1989). Biology and epidemiology. In: Coffee Rust: Epidemiology, Resistance and Management. A.C. Kushalappa and A.B. Eskes, eds. CRC Press, pp. 13-80.

[3] Monroig-Inglés, M. (1988). Prácticas Modernas en el Cultivo del Café en Puerto Rico. SEA, Colegio de Ciencias Agrícolas, Recinto Universitario de Mayagüez. Mayagüez, PR: Banco Santander de Puerto Rico. 
[4] SAS Institute, Inc. (1990). SAS Guide to Macro Processing. Version 6, Second edition. Cary, NC: SAS Institute, Inc.

[5] SAS Institute, Inc. (1997). SAS/STAT Software: Changes and Enhancements through Release 6.12. Cary, NC: SAS Institute, Inc.

[6] Schwarz, G. (1978). Estimating the dimension of a model. Annals of Statistics 6, 461464 .

[7] Steel, R. and J. Torrie (1980). Principles and Procedures of Statistics: A Biometrical Approach. New York: McGraw-Hill.

[8] Wolter, K. (1984). Introduction to Variance Estimation. New York: Springer-Verlag.

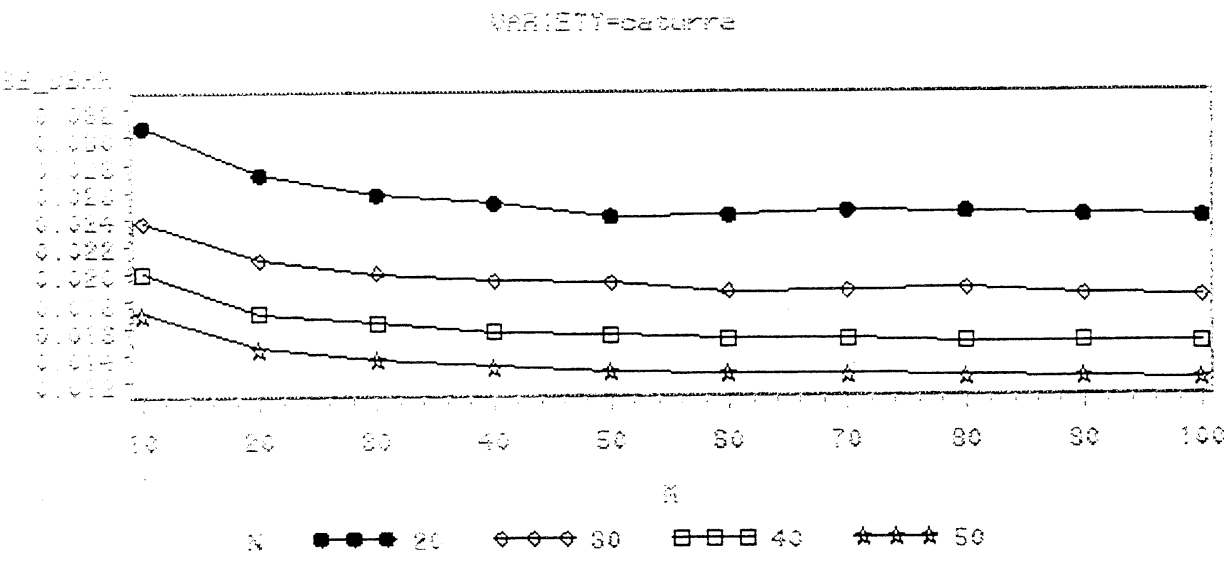

Figure 1: Standard errors of the estimated disease index $(m=$ number of leaves/tree, $\mathrm{n}=$ number of trees) 
WE:ET:-20:bor:

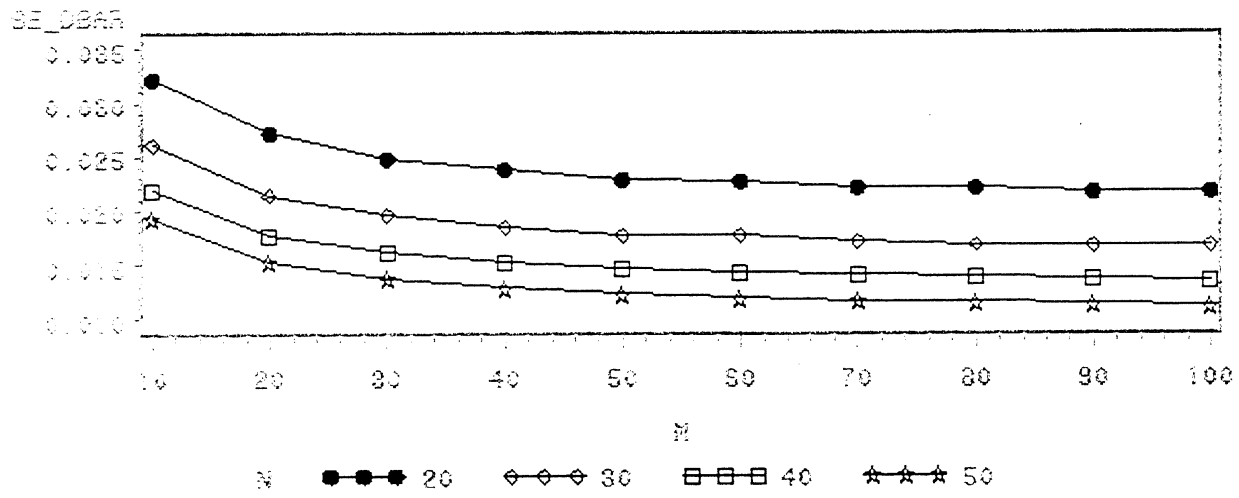

Figure 2: Standard errors of the estimated disease index ( $\mathrm{m}=$ number of leaves/tree, $\mathrm{n}=$ number of trees).

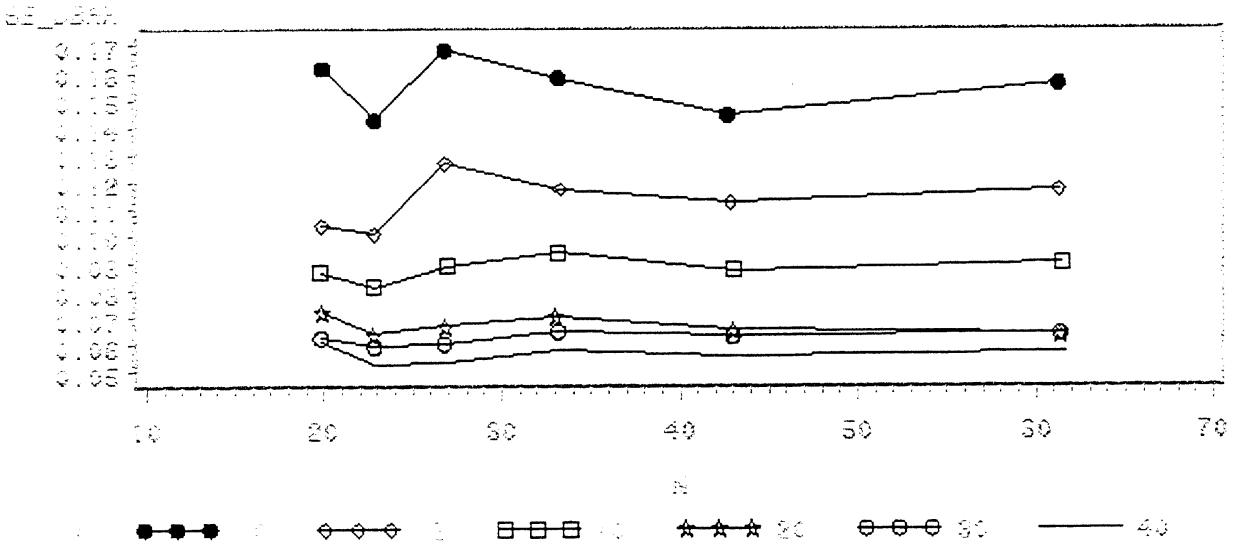

Figure 3: Standard errors of estimated disease index for samples in parallel rows ( $m=$ number of leaves/tree, $n=$ number of trees). 
(1)

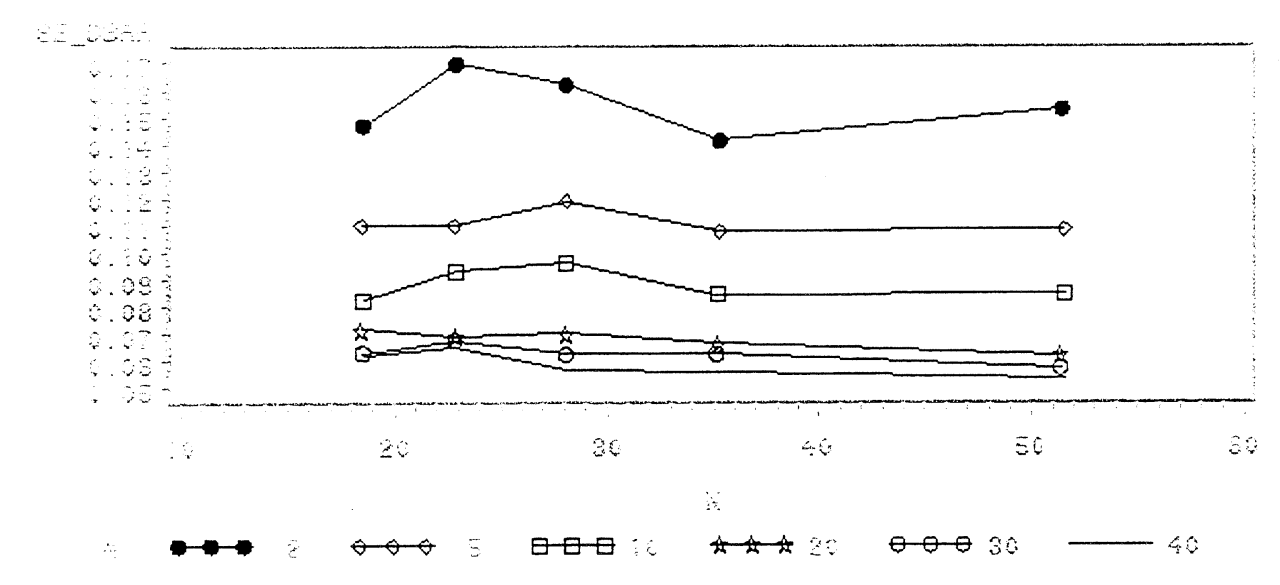

Figure 4: Standard errors of estimated disease index for samples in a $\mathrm{W}$ pattern $(\mathrm{m}=$ number of leaves $/$ tree, $\mathrm{n}=$ number of trees). 